\title{
Nano Crystallites and Clustered Species in Modified Sodium Telluride Glasses.
}

Amal Behairy

The High institute of Engineering and Technology in New Damietta, Egypt

\begin{abstract}
The structural properties, crystalline and clustering behavior of $x \mathrm{Na}_{2} \mathrm{O} \cdot(1-x) \mathrm{TeO}_{2}(15 \leq x \leq 65 \mathrm{~mol} \%)$ glasses have been investigated by FTIR spectroscopy, X-ray diffraction (XRD), differential scanning calorimetry (DSC) and scanning electron microscopy (SEM). The experimental results have demonstrated that the basic structural units in telluride glasses change from highly strained $\mathrm{TeO}_{4}$ trigonal bipyramids to more regular $\mathrm{TeO}_{3}$ units containing non bridging oxygen atoms (NBO). The concentration of NBO atoms in telluride network increases with increasingl $\mathrm{Na}_{2} \mathrm{O}$ content. The present results suggest that (NBO) atoms in telluride glasses exist in their pure form in compositions of up to $35 \mathrm{~mol} \% \mathrm{Na}_{2} \mathrm{O}$. But at higher $\mathrm{Na}_{2} \mathrm{O}$ concentrations, NBO atoms do not exist in their pure form; that is, the majority of NBO atoms are coordinated with high concentration from $\mathrm{Na}$ cations to form nano-crystalline clusters. The results based on X-ray diffraction (XRD), scanning electron microscopy (SEM) and differential scanning calomerty (DSC) reveal the presence of two crystalline phases: $\alpha \mathrm{TeO} 2$ and $\mathrm{Na}_{2} \mathrm{Te}_{4} \mathrm{O}_{9}$ phases during the crystallization process of the prepared glass in the region $<50 \mathrm{~mol} \% \mathrm{Na}_{2} \mathrm{O}$. But at higher $\mathrm{Na}_{2} \mathrm{O}$ concentrations, $\mathrm{Na}_{2} \mathrm{Te}_{2} \mathrm{O}_{5}$ and $\mathrm{NaTeO}_{3}$ crystalline clustered phases in the nono size scale are the dominant types. This means that NBO in $\mathrm{TeO} 3$ trigonal pyramids will interact with the excess of $\mathrm{Na}$ cation resulting in the three-dimensional network containing nano size clusters particularly in telluride glasses containing 50 and $65 \mathrm{~mol} \% \mathrm{Na}_{2} \mathrm{O}$. An increase in $\mathrm{Na}_{2} \mathrm{O}$ concentration in $\mathrm{Na}_{2} \mathrm{O}$-rich telluride network results in increasing $\mathrm{Na}$ coordination instead of breaking more tellurium-oxygen bonds.
\end{abstract}

\section{Keywords}

Crystalline species, Clustered phases, Spectroscopy, Glasses

Date of Publication: 11-08-2018

DOI: 10.24297/jap.v14i2.7523

ISSN: 2347-3487

Volume: 14 Issue: 2

Journal: Journal of Advances in Physics

Website: https://cirworld.com

This work is licensed under a Creative Commons Attribution 4.0 International License. 


\section{1- Introduction}

The structure of binary and ternary telluride glasses [1-5] has been investigated extensively by a variety of experimental techniques $[5,6]$. It has been reported that the structure of $\mathrm{TeO}_{2}$ glasses with a small amount of $\mathrm{Na}_{2} \mathrm{O}$ (up to 20 moles \%) is a continuous random network of $\mathrm{TeO}_{4}$ trigonal bipyramids (tbps) and $\mathrm{TeO}_{3+1}$ polyhedra having one nonbridging oxygen, $\mathrm{NBO}$. In glasses containing 20-30\% mole $\% \mathrm{Na}_{2} \mathrm{O}$, with increasing NBOs, the $\mathrm{TeO}_{3}$ trigonal pyramids (tps) are formed in the continuous network. At nearly $50 \%$ mole of modifier oxide the glass structure consists of $\mathrm{TeO}_{3+1}$ polyhedra and $\mathrm{TeO}_{3}$ tps along with the isolated $\mathrm{Te}_{2} \mathrm{O}_{5}{ }^{2-}$ and $\mathrm{TeO}_{3}{ }^{2-}$ units. There are some types of crystalline phases appeared in glass of $50 \mathrm{~mol} \% \mathrm{Na}_{2} \mathrm{O}$. Which is indexed to $\left(\mathrm{Na}_{2} \mathrm{TeO}_{3}\right)$ [4,5]. Formation of such stable crystalline phases is confirmed to be related to the high concentration of NBO atoms in telluride as well as in silicate glasses [4]. In general, the structure of alkali telluride glass was tellurium atom (Te) bonded to four oxygen atoms. Some of oxygen atoms were bonded to two Te atoms (bridging oxygen, $\mathrm{BO}$ ) and some to only one Te atom (NBO) $[4,7$, and 8]. The alkali ions were arranged in random holes throughout the tellurium oxygen network. The modifier oxide such as $\mathrm{Na}_{2} \mathrm{O}$ is consumed for the replacement of a $\mathrm{BO}$ with two NBOs upon addition of each $\mathrm{Na}_{2} \mathrm{O}$. The negative charge of the NBOs is therefore balanced by the positively charged sodium cation in order to maintain charge neutrality. This reflects that each $\mathrm{Na}$ atom is associated with one NBO atom. As a consequence, in pyro-telluride glasses, there are two types of oxygen, $\mathrm{BO}$ and $\mathrm{NBO}$. But in glasses rich with higher modifier (orthotellerate composition $>50 \mathrm{~mol} \%$ ), the structural role of $\mathrm{Na}_{2} \mathrm{O}$ is not clear and no studies on network modification in such a case is reported. Some studies $[4,9]$ were carried out on modified silicate and borosilicate glasses enriched with $\mathrm{Na}_{2} \mathrm{O}$ and it was evidenced that some of crystalline clusters from the modifier such as $\mathrm{Na}$ can be constructed by the effect of NBO.

\section{2- Experimental}

\section{1 sample preparation}

Glasses of compositions $x \mathrm{Na}_{2} \mathrm{O} \cdot(100-x) \mathrm{TeO}$, mol\%, with $x=15,25,35,50,65$ were prepared by melting wellmixed, high-purity raw materials of $\mathrm{TeO}_{2}(99.99 \%)$ and $\mathrm{Na}_{2} \mathrm{CO}_{3}(99.95 \%)$ in a silica crucible at $850{ }^{\circ} \mathrm{C}$ for $1 \mathrm{~h}$ in air. The met was then quenched between two stainless steel plates. The as obtained glasses were immediately stored in a vacuum desiccator until used for measurements.

\subsection{Experimental Techniques and Measurements}

X-ray diffraction measurements were carried out on powdered samples using a Bruker D8 Advance powder XRD system with a $\mathrm{Cu} \mathrm{K} \cdot$ - radiation. The range of the diffraction angle $(2 \cdot$ - is changed from from $5^{\circ}$ to $80^{\circ}$ using a dwell time of 0.4 seconds. The X-ray diffraction is used to confirm the amorphous or crystalline nature of the material structure.

FTIR Spectra were obtained in the wavenumber range of 400 to $4000 \mathrm{~cm}^{-1}$ using a Mattson 5000 FTIR Spectrometer. Each sample was mixed with $\mathrm{KBr}$ by the ratio 1:100 in weight and then pressed to produce a homogeneous pellet. The infrared absorbance measurements are measured at room temperature and immediately after preparing the pellets.

Scanning electron microscopy is widely used to examine surface modifications and microstructure of specimens using (JEOL SEM Model, JSM-5610 LV). In this measurement, a beam of electrons is focused on a spot volume of the specimen, resulting interaction of the beams with the surface of the sample. The scattered electrons can be detected and provide information on surface morphology.

The energy dispersive X-ray spectra (EDX) of the samples were also acquired during their scanning electron microscopic (SEM) measurement. EDX is based on the detection of the emitting of $x$-rays by the elements of the sample as a result of the ejected inner shell electrons using a high energy electron beam. The EDX spectrum normally displays peaks corresponding to how frequently an X-ray is received for each energy level in the single element. The higher concentrated elements in the sample present the most intense peaks in the spectrum. This technique is widely used for identifying the elemental composition of the sample. 


\section{Results and Discussion}

It was reported recently $[4,9,10]$ that alkali lead silicate or borosilicate glasses containing extremely high concentration from modifier oxide and NBO can simply form cluster species from the modifier captions around the NBO. The well formed clusters can be distributed in a specific manner which allows to some percolation channels or pathways to be formed in the main glass network. The micro-segregations of the modifier oxide $\left(\mathrm{Na}_{2} \mathrm{O}\right)$ is dominant in glasses enriched with modifier oxide, i.e., of concentration greater than $30 \mathrm{~mol} \%$. But at lower concentration, $\mathrm{Na}_{2} \mathrm{O}$ is consumed as an ordinary modifier creating $\mathrm{NBO}$ atom in the main glass network without any tendency toward building any types of ordered clustered species.

The above consideration is supported to a great extent by the present experimental studies of $\mathrm{Na}_{2} \mathrm{O}$ rich telluride glasses, since the obtained results have showed that $\mathrm{Na}$ can play a role of a clustering agent when the concentration of $\mathrm{Na}_{2} \mathrm{O}$ is relatively high ( $\geq 35 \mathrm{~mol} \%$ ). As a result of presence of high contents of modifier oxide, telluride polyhedral units such as isolated $\mathrm{Te}_{2} \mathrm{O}_{5}{ }^{2-}$ and $\mathrm{TeO}_{3}{ }^{2-}$ groups with $\mathrm{NBO}$ atoms are formed. Such units can activate both crystallization and clustering process in the main glass network [4, 9].

\subsection{DSC Thermal analysis}

The DSC curves of the investigated glasses in this study are shown in figures 1 and 2 . As presented by figure $1(\mathrm{a})$, the DSC curve for the glass containing $15 \%$ mole\% of $\mathrm{Na}_{2} \mathrm{O}$ shows sharp crystallization peak at $320^{\circ} \mathrm{C}$ indicating crystallization of a single crystalline phase of the type $\mathrm{Na}_{2} \mathrm{Te}_{4} \mathrm{O}_{9}[1,11,12]$. But glass with 35 $\%$ mole $\% \mathrm{Na} 2 \mathrm{O}$ contains a broad asymmetric exothermic peak at $\approx 345^{\circ} \mathrm{C}$, figure $1(\mathrm{~b})$. This broad shape of the crystallization peak may be attributed to simultaneous crystallization of more than one phase. It is well known, that sharp crystallization peak implies a higher order reaction due to bulk crystallization of three dimensional growths. While a broad peak signifies a lower order due to surface crystallization of one dimensional growth [13].

Glasses of higher $\mathrm{Na}_{2} \mathrm{O}$ concentrations ( 50 and $65 \mathrm{~mol} \%$ ) showed different crystallization peaks figure $2(a, b)$. These exothermic peaks corresponding to the aggregation of different crystalline cluster species [13, 14]. As a result of crystallization process, the one specific phase in the parent glass ( $15 \mathrm{~mol} \% \mathrm{Na} 2 \mathrm{O})$ is transformed into new crystalline phases represented by the appearance of more additional exothermic peaks in glasses enriched with $\mathrm{Na}_{2} \mathrm{O}$ (50 and 60 mol\%) see figure 2 (alb). Such ego thermal peaks are typical for glasses with high crystallization tendency and also give preliminary guidance for the structure changes to obtain clustered glasses or glass ceramics [14]

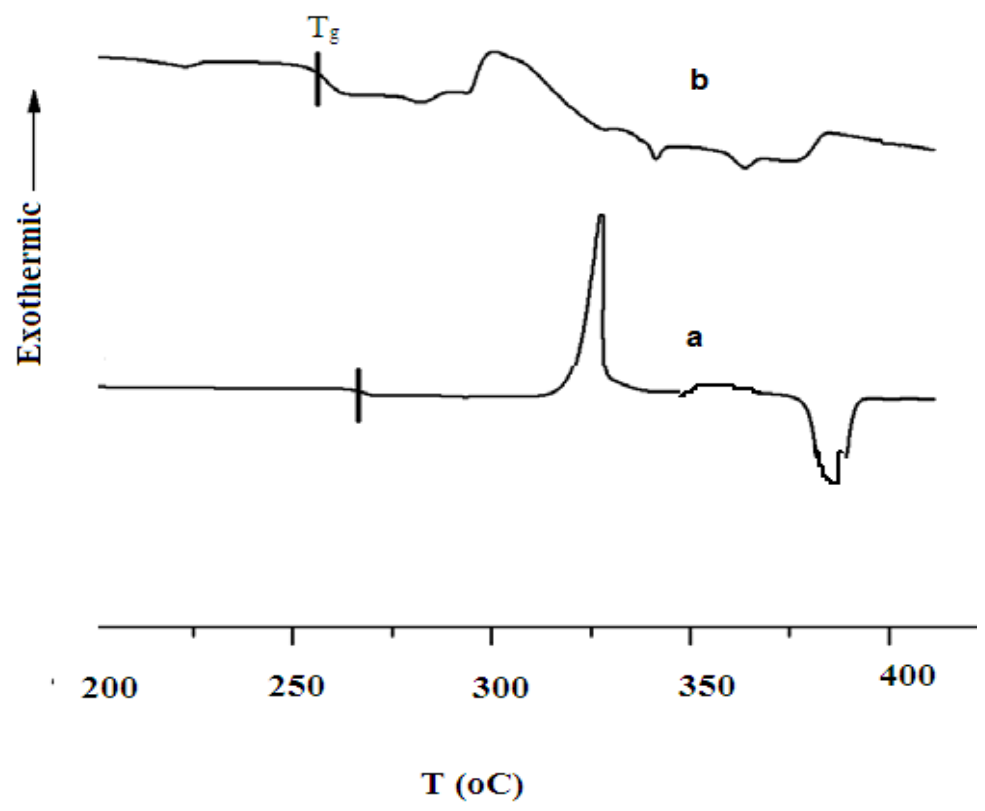

Figure 1 Differential scanning calometry for glasses containing $\mathrm{Na}_{2} \mathrm{O}$. A (20 mol \%.), b (35mol \%) 


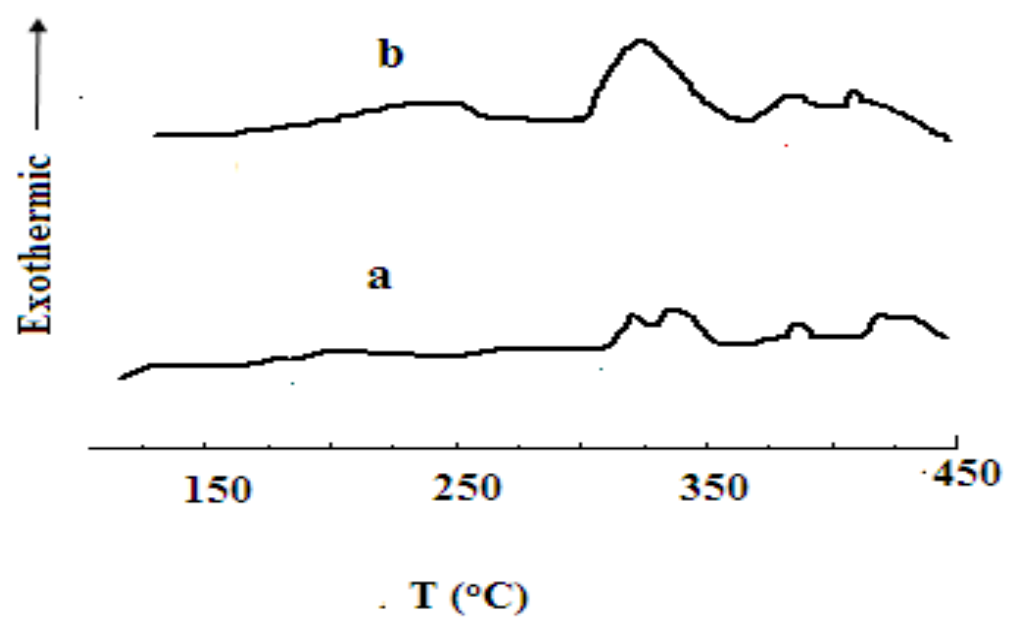

Figure 2 Differential scanning calometry for glasses containing $\mathrm{Na}_{2} \mathrm{O}$. A (50 mol \%.), b (65mol \%)

It can be also noticed that the position of exothermal peak shifts toward higher temperature with increasing $\mathrm{Na}_{2} \mathrm{O}$ concentration. In addition, more exothermic peaks are found in glasses containing higher $\mathrm{Na}_{2} \mathrm{O}$ concentrations (50,65 mol \%) (Figure 2) in comparison with glasses of lower $\mathrm{Na}_{2} \mathrm{O}$ concentration (figure 1). These differences may be attributed to formation of different types of nano-size clusters or crystallites of $\mathrm{Na} 2 \mathrm{Te} 4 \mathrm{O} 9$ and $\mathrm{Na}_{2} \mathrm{TeO}_{3}$ species whose concentration increases with increasing the $\mathrm{Na}_{2} \mathrm{O}$ content $[1,12-14]$.

\subsection{XRD Analysis}

Figure 3 shows changes of XRD spectra with change of glass composition. The spectrum for the as prepared pure vitreous $\mathrm{TeO}_{2}$ is also shown (figure 4) for comparison. The spectrum of pure $\mathrm{TeO}_{2}$ glass ( figure 4 ) is dominated by several diffraction peaks which may be assigned to ordered $\mathrm{TeO}_{2}$ network made of chain - like fragments, consisting of the rather symmetric Te-O-Te bridges and Te-O terminal bonds [1-7]. The more ordered structure is disrupted to great extend by adding $\mathrm{Na}_{2} \mathrm{O}$ in the region (20-35 mol \%), figure 3(a,b) and then recrystallization is appeared again at higher $\mathrm{Na}_{2} \mathrm{O}$ concentration. More crystalline structure is considered in $\mathrm{Na}_{2} \mathrm{O}$ rich glasses, see figure $3(\mathrm{c}, \mathrm{d})$.

The interpretations based on the data of DSC techniques are highly confirmed by XRD results based on X-Ray spectroscopy of the same glasses. It can be concluded from figure 3(a) that the amorphous structure is confirmed in glasses of up to $30 \mathrm{~mol} \% \mathrm{Na}_{2} \mathrm{O}$. On the other hand, crystalline structure is evidenced upon more $\mathrm{Na}_{2} \mathrm{O}$ addition, since it can be seen from figure 3 that XRD spectra of glasses of relatively high content of modifier oxide contain several components of sharp diffraction lines. This means that the crystallinity is enhanced via increasing $\mathrm{Na}_{2} \mathrm{O}$ content which is considered due to increase the aggregation of $\mathrm{Na}$ around NBO atoms [4]. According to JCPDS data, the small diffraction peaks in the XRD pattern of glass containing 15 and $25 \mathrm{~mol} \% \mathrm{Na}_{2} \mathrm{O}$ correspond to those for $a-\mathrm{TeO}_{2}$ (PDF 42-1365), whereas for crystallized glass containing more higher $\mathrm{Na}_{2} \mathrm{O}$ content (35- 65 mol\%) involves diffraction pattern of additional peaks which are indexed and related to $\mathrm{Na}_{2} \mathrm{Te}_{4} \mathrm{O}_{9}$ (PDF 32-1166), $\mathrm{Na}_{2} \mathrm{Te}_{2} \mathrm{O}_{5}$ and $\mathrm{Na}_{2} \mathrm{TeO}_{3}$ [15]. Presence of such crystalline phases is expected since these glasses are enriched with modifiers and NBO atoms which activate the aggregation of $\mathrm{Na}$ cation around NBO atoms forming aggregated crystalline species enriched with sodium [4].

However, the little diffraction peaks for lower values of $\mathrm{Na}_{2} \mathrm{O}(20 \mathrm{~mol} \%)$ do not match with the peaks for $\mathrm{Na}_{2} \mathrm{Te}_{2} \mathrm{O}_{5}$ but the peak at about $12^{\circ}$ may be related to $\mathrm{Na} 2 \mathrm{TeO} 4$ available in the JCPDS files. 


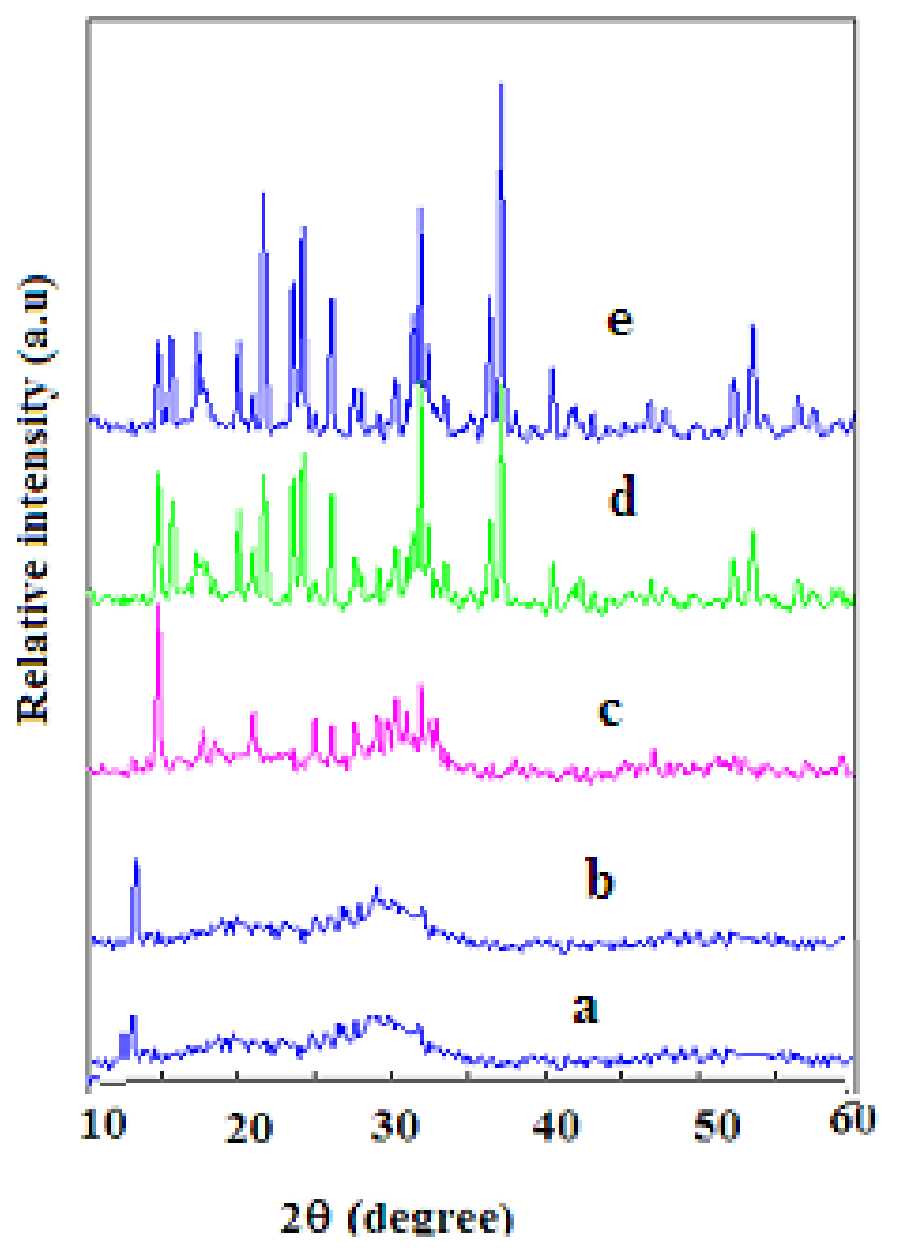

Figure 3 XRD patterns for glasses containing $\mathrm{Na}_{2} \mathrm{O}$. a (20 mol\%.), b (25 mol\%), C( $35 \mathrm{~mol} \%$ ) and d (50 mol\% ) and e (65 mol\%).

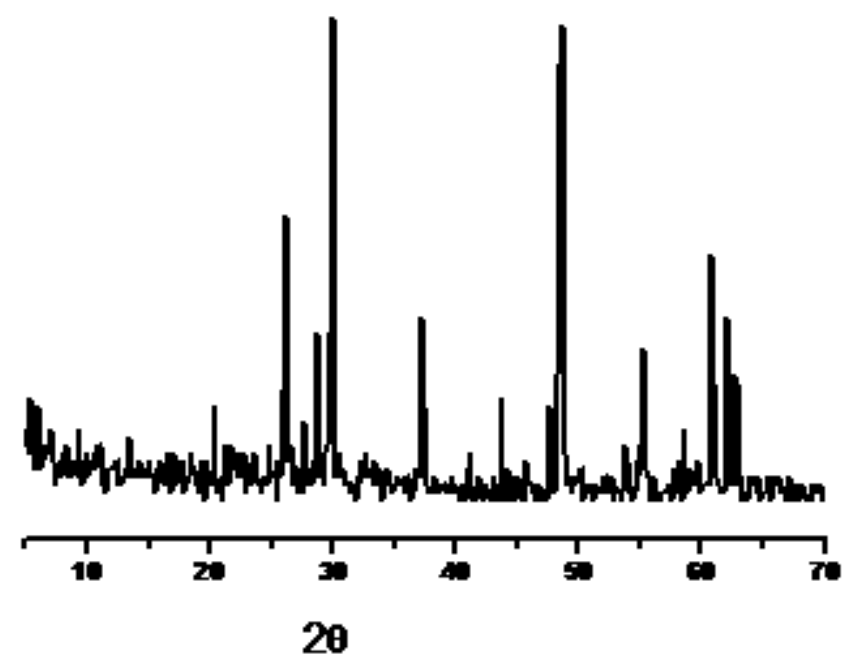

Figure 4 XRD pattern of pure $\mathrm{TeO}_{2}$ glass 


\subsection{FTIR spectroscopy}

Figure 5 shows the infrared absorption spectra for the sodium telluride glass samples in the $400-4000$ $\mathrm{cm}^{-1}$ range. The spectrum for prepared pure vitreous $\mathrm{TeO}_{2}$ is also shown for comparison. The spectrum of $\mathrm{TeO}_{2}$ glass (plot an in figure 5) is dominated by two absorption bands at 775 and $660 \mathrm{~cm}^{-1}$. The band at 775 $\mathrm{cm}^{-1}$ is assigned to the symmetric equatorial $\left(\mathrm{TeO}_{2}\right)_{\text {eq }}$ vibration, while the broad non-symmetric band at 660 $\mathrm{cm}^{-1}$ may represent symmetric and asymmetric axial $\left(\mathrm{TeO}_{2}\right)_{\mathrm{ax}}$ stretching modes of $\mathrm{TeO}_{4}$ units $[4,6,11,12]$. It was suggested that, the $\mathrm{TeO}_{2}$ glass is made of chain - like fragments, consisting of the rather symmetric Te-O$\mathrm{Te}$ bridges (responsible for the band near $775 \mathrm{~cm}^{-1}$ ), and of the Te-O terminal bonds. The latter type of bonds interconnects the neighboring chains via very asymmetric Te- $\mathrm{O}_{\text {terminal }}-\mathrm{Te}$. The bending vibrations of those bonds account for the band near $660 \mathrm{~cm}^{-1}[1-$ 6].

FTIR absorbance spectra (figure 6. plot b, $c, d$ and e) show that the addition of $\mathrm{Na}_{2} \mathrm{O}$ to $\mathrm{TeO}_{2}$ glass affects the obtained spectra. Generally, the feature of FTIR spectra is changed upon increasing $\mathrm{Na}_{2} \mathrm{O}$ concentration as is seen from figure 6. The observed trend is that as $\mathrm{Na}_{2} \mathrm{O}$ content increases at expense of $\mathrm{TeO}_{2}$, the high frequency absorption peak $\left(1500 \mathrm{~cm}^{-1}\right)$ showed a gradual increase. Moreover, the spectrum line-shape changes clearly when $\mathrm{Na}_{2} \mathrm{O}$ content varies between $0-65$ molpercent. The most to be noted is that the absorbance band found around $1500 \mathrm{~cm}^{-1}$ becomes more resolved in glasses of high $\mathrm{Na}_{2} \mathrm{O}$ contents (50 and $65 \mathrm{mo} \%$ ). Quantitively, the relative area of this band increases with increasing $\mathrm{Na}_{2} \mathrm{O}$ content as represented in (Figure 7). Same behavior was found in silicate glasses rich with $\mathrm{Na}_{2} \mathrm{O}$ [4-6]. In such situation, there are two phases are formed upon increasing $\mathrm{Na}_{2} \mathrm{O}$ contents. Na-rich regions and tellurium rich phase. These tow distributions can be extended in three dimension to form sodium and NBO rich channels within tellurium rich regions. It is consequently considered that an inhomogeneous distribution of structural groups would be formed in the glass matrix. The non-bridging oxygen atoms can simply provide specific structural links between two sub-structural units, with the result that $\mathrm{Na}$ atoms cluster around the NBO resulting in the formation of percolation channels. The micro-segregations of $\mathrm{Na}_{2} \mathrm{O}$ from $\mathrm{SiO}_{2}$ or $\mathrm{TeO}_{2}$ are more significant for sodium concentration greater than $30 \mathrm{~mol} \%$. As is seen from FTIR spectra, the resolving of absorbance band around $1500 \mathrm{~cm}^{-1}$ in glasses of 50 and $65 \mathrm{~mol} \% \mathrm{Na}_{2} \mathrm{O}$ confirms the formation of crystallized aggregated clusters from $\mathrm{Na}_{2} \mathrm{O}$. This consideration is supported to great extent by the present experimental studies of $\mathrm{Na}$ rich telluride glasses, since the obtained results show that $\mathrm{Na}$ is clustering and consequently the extended glass network is heterogeneous when the concentration of $\mathrm{Na}_{2} \mathrm{O}$ is high ( $\geq 50 \mathrm{~mol} \%$ ).

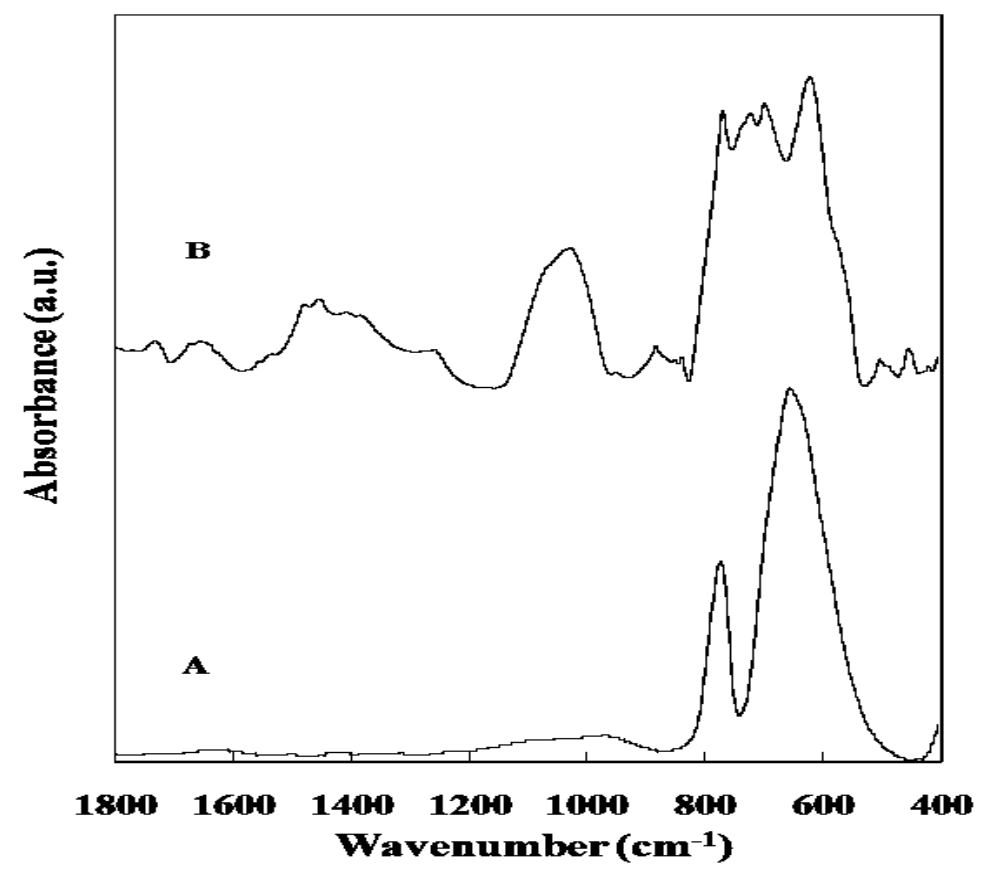


Figure 5 the infrared absorption spectra for pure $\mathrm{TeO} 2(\mathrm{~A})$ and of the sodium telluride glass sample (B) in the $400-4000 \mathrm{~cm}^{-1}$ range

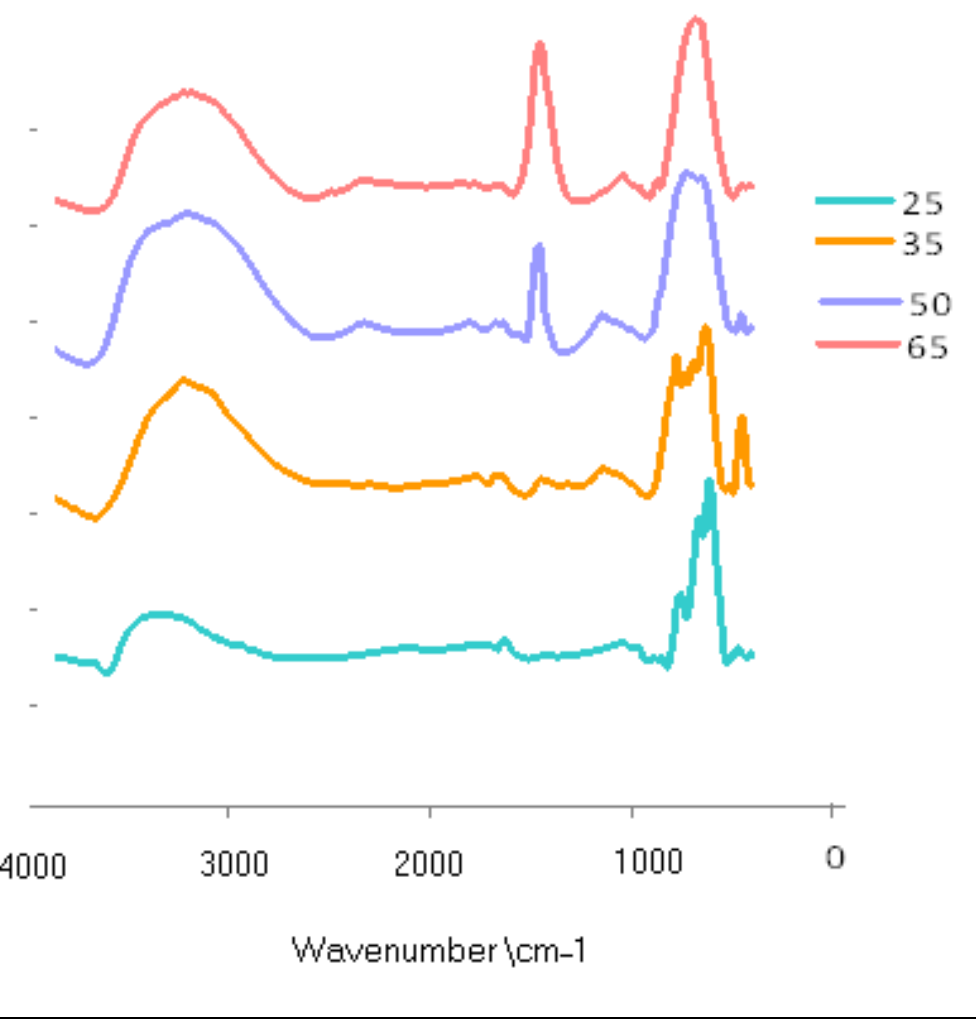

Figure 6 FTIR spectra for glasses containing different $\mathrm{Na}_{2} \mathrm{O}$ concentrations

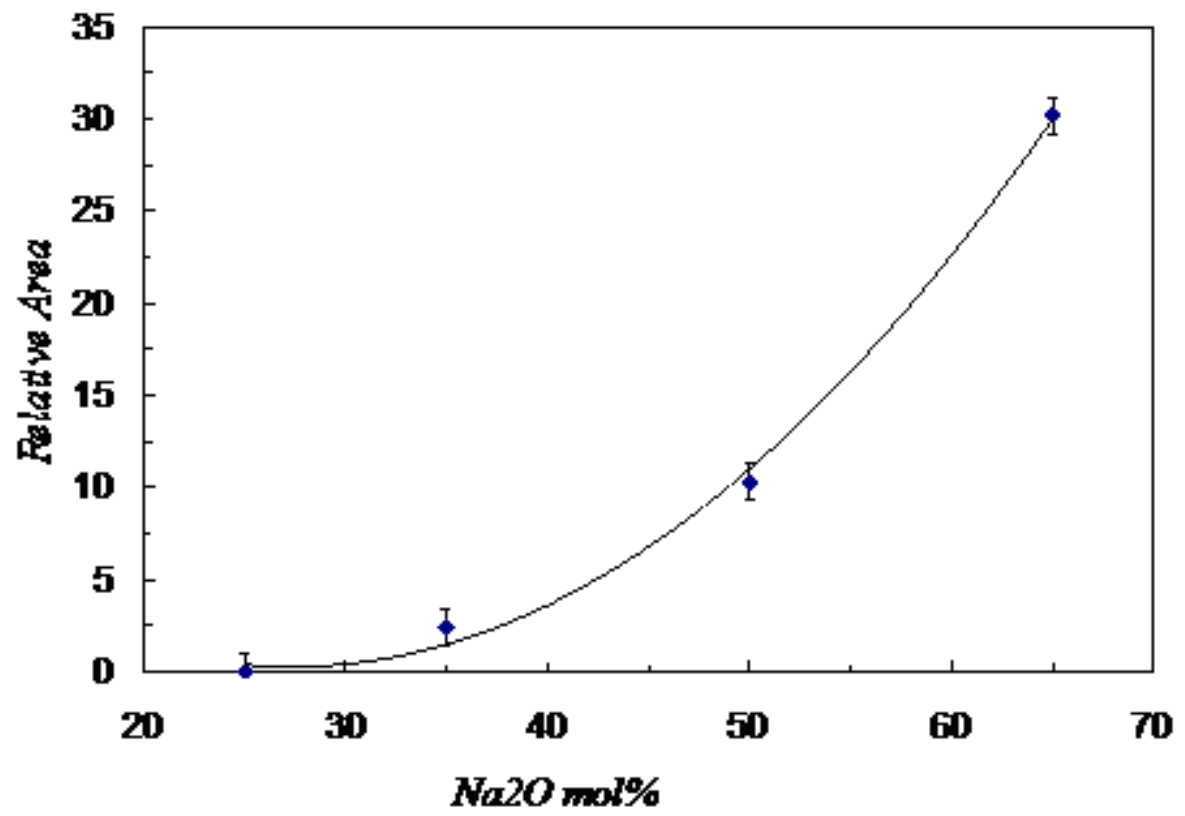

Figutr 7 Change of relative area of FTIR peak at $1500 \mathrm{~cm}^{-1}$ with $\mathrm{Na}_{2} \mathrm{O}$ concentration

Moreover, appearance of new peak at about $1400 \mathrm{~cm}^{-1}$ in glasses rich with $\mathrm{Na}_{2} \mathrm{O}$ ( $\geq 50 \mathrm{~mol} \%$ ) and the peaks around $505-455 \mathrm{~cm}^{-1}$ indicate the formation or precipitation of fused $\mathrm{Na}_{2} \mathrm{O}$ clusters [4-6]. The increasing of cluster concentration results in increasing relative area of the peaks centered around $1400 \mathrm{~cm}^{-1}$. 
Moreover the splitting of the absorption bands at 455, 505, 1048 and $1097 \mathrm{~cm}^{-1}$ [4-8] is transformed to one resolved peak which may be assigned to segregation and separation of $\mathrm{Na}_{2} \mathrm{O}$ phases deposited on amorphous $\mathrm{TeO}_{2}$ network This band shifts to a position between 1456 and $1481 \mathrm{~cm}^{-1}$ which is due to distribution of different $\mathrm{Na}$ sites that depend on nucleation, segregation and formation of $\mathrm{Na}_{2} \mathrm{O}$ cluster [4-6].

It is therefore deduced that formation of a new resolved band at $1400 \mathrm{~cm}^{-1}$ especially at high $\mathrm{Na}_{2} \mathrm{O}$ concentration and transformation of the splitted peaks $\left(600-800 \mathrm{~cm}^{-1}\right)$ to one resolved absorption spectrum may be related to formation of separated clusters [4-6], which was documented by SEM morphology and XRD results

The development of the first sharp absorption peak of sodium tellurate glasses at $1400 \mathrm{~cm}^{-1}$ which increase with increasing $\mathrm{Na}_{2} \mathrm{O}$ contents was interpreted on basis of heterogeneous $\mathrm{Na}$ distribution in the network of the glass.

\subsection{SEM-EDS Investigation}

SEM-EDS investigations were performed on some selected glass compositions in order to identify changes in morphology and chemical composition of the investigated samples. Three selected samples, one of low $\mathrm{Na}_{2} \mathrm{O}$ content $(20 \mathrm{~mol} \%)$ and the other samples contain the highest $\mathrm{Na}_{2} \mathrm{O}$ concentration (50 and $65 \mathrm{~mol} \%$ ) have been chosen.

The SEM micrograph in Figure 8 for the glasses containing 20 mole Na2O showing homogeneous glassy phase which is typical for the low $\mathrm{Na}_{2} \mathrm{O}$ composition. The corresponding EDS analysis showed identical spectra confirming homogeneous character of the sample. This result is further supported from XRD pattern of the glass of the same composition $\left(20 \mathrm{~mol} \% \mathrm{Na}_{2} \mathrm{O}\right)$, since no crystals were detected by XRD spectroscopy. The chemical composition calculated from EDS spectra of glass of 20 mol\% $\mathrm{Na}_{2} \mathrm{O}\left(19.5 \%\right.$ mole of $\mathrm{Na}_{2} \mathrm{O}$ and $79 \pm 0.5 \%$ mole $\%$ of $\mathrm{TeO}_{2}$ ) is in excellent agreement with nominal composition of the glass.

Figure 9 shows the SEM micrograph taken from the surface of the crystallized glass containing 50 and $65 \%$ mole \% of $\mathrm{Na}_{2} \mathrm{O}$. The morphology of the samples consists of hexagonal-shaped crystals with diameter ranging from 5 to $10 \mathrm{~mm}$. Based on the EDS analysis, observed crystals are Cleary observed indicating crystallization of phase with $\mathrm{Na}_{2} \mathrm{Te}_{2} \mathrm{O}_{5}$ stoichiomery which is fitted and matched with the pattern for $\mathrm{Na}_{2} \mathrm{Te} 2 \mathrm{O} 5$ available in JCPDS files, so it seems that the observed crystals correspond to a new $\mathrm{Na}_{2} \mathrm{Te}_{2} \mathrm{O}_{5}$ polymorph.

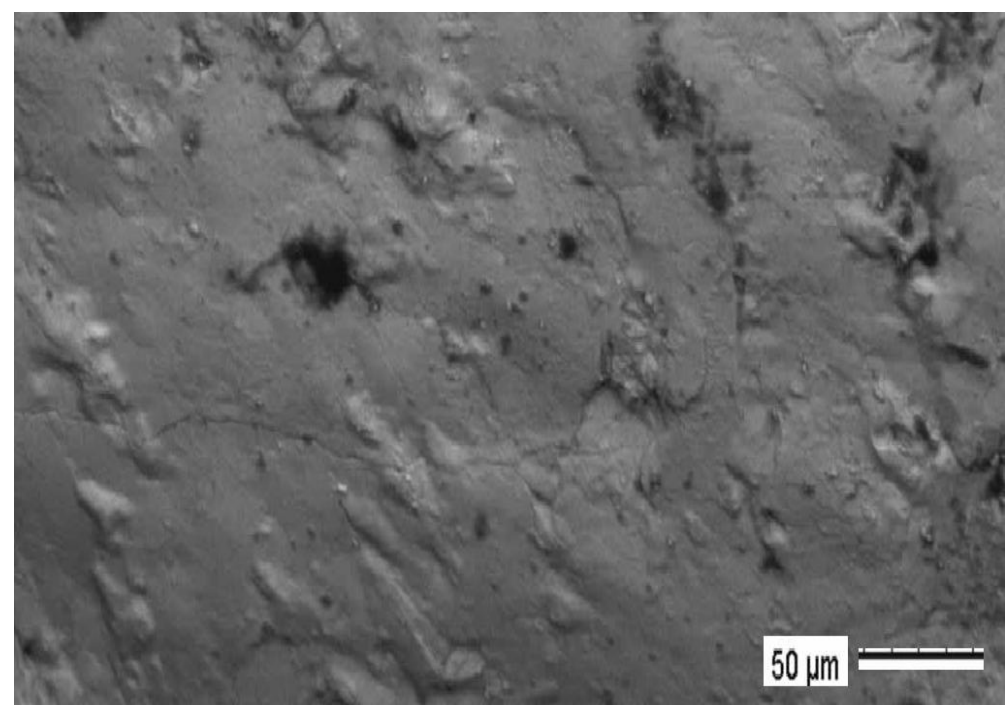

(20 mol \%) 


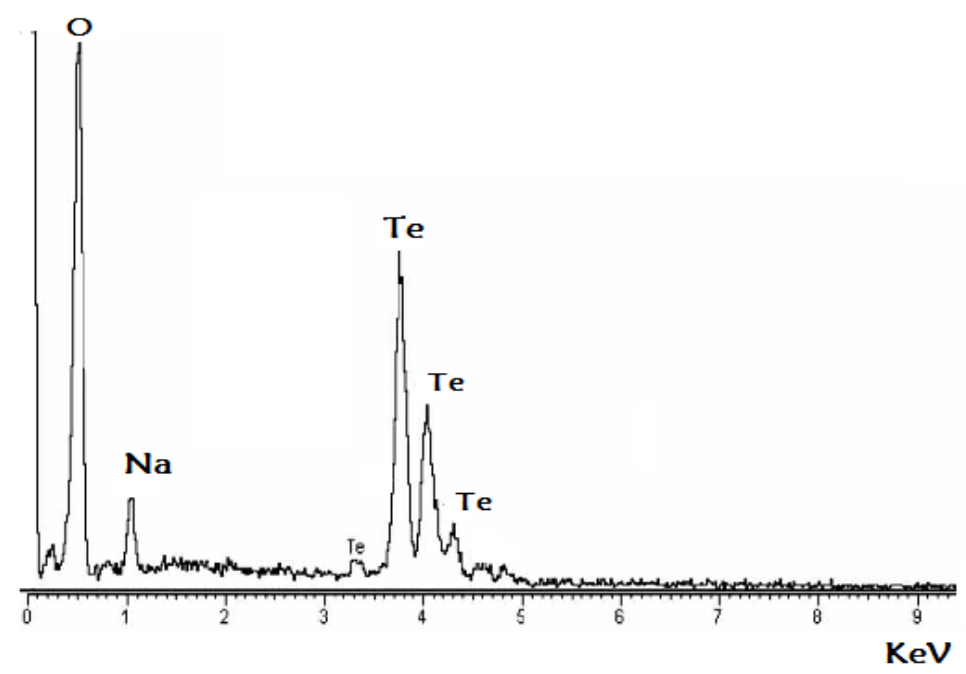

Figure 8 SEM and ED's spectra for glass containing $20 \mathrm{~mol} \% \mathrm{Na}_{2} \mathrm{O}$

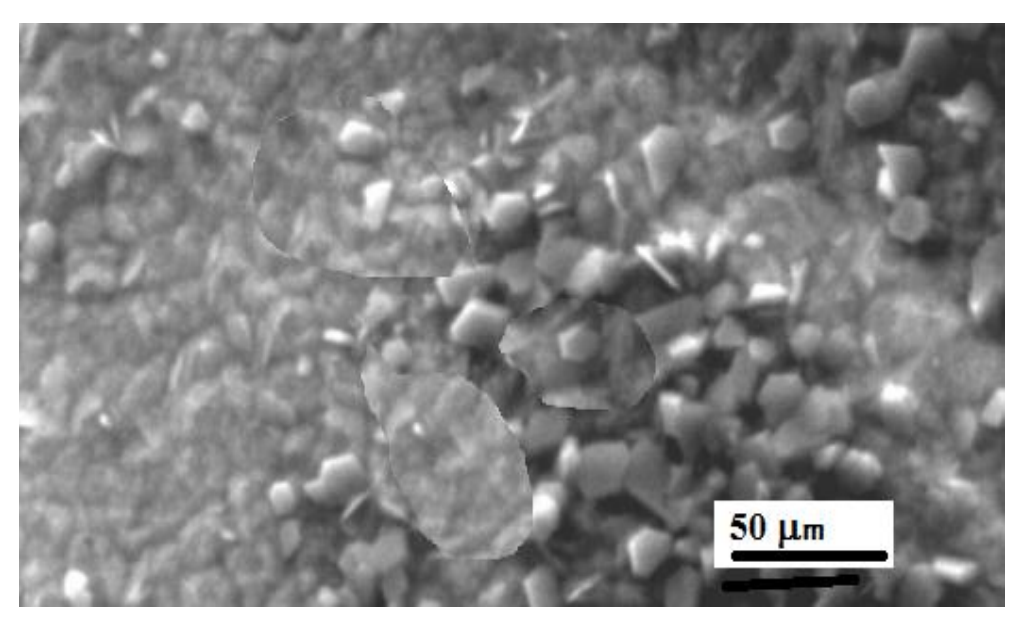

(50 $\mathrm{mol} \%$ )

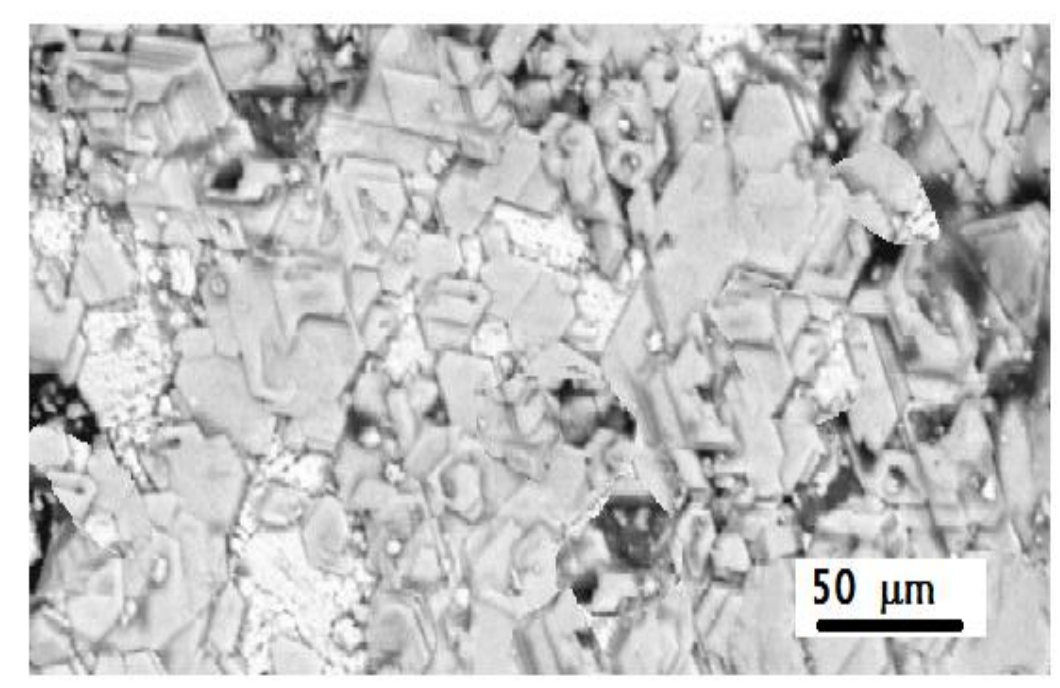

(65 mol \%) 


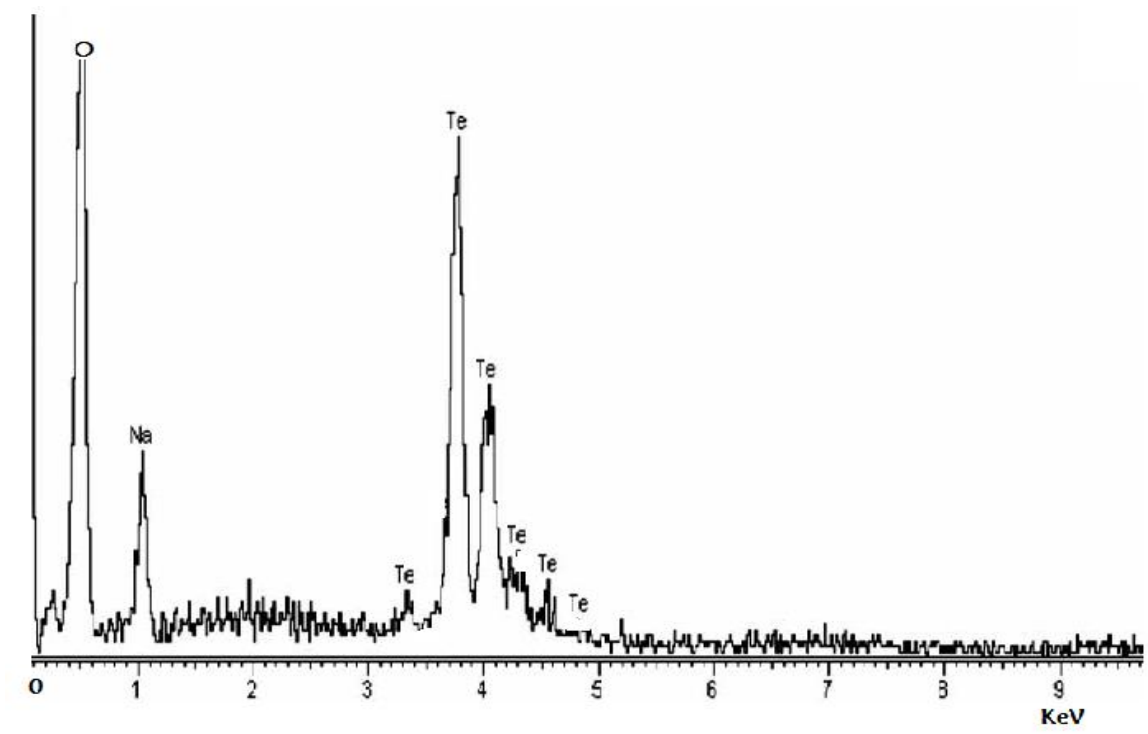

Figure9 SEM and EDS spectra for glass containing 50 and $60 \mathrm{~mol} \% \mathrm{Na}_{2} \mathrm{O}$

\section{4- Conclusion}

The obtained results have demonstrated that the basic structural units in telluride glasses change from highly strained $\mathrm{TeO}_{4}$ trigonal bipyramids to more regular $\mathrm{TeO}_{3}$ units containing non bridging oxygen atoms (NBO). The concentration of NBO atoms increases with increasing $\mathrm{Na}_{2} \mathrm{O}$ content. (NBO) atoms in telluride glasses exist in their pure form in glasses of up to $35 \mathrm{~mol} \% \mathrm{Na}_{2} \mathrm{O}$. But at higher $\mathrm{Na}_{2} \mathrm{O}$ concentrations, NBO atoms do not exist in their pure form; that is, the majority of NBO atoms are coordinated with high concentration from $\mathrm{Na}$ cation to form nano-crystalline clusters. X-ray diffraction (XRD), scanning electron microscopy (SEM) and differential scanning calomerty (DSC) reveal the presence of two crystalline phases: $\alpha$ $\mathrm{TeO}_{2}$ and $\mathrm{Na}_{2} \mathrm{Te}_{4} \mathrm{O}_{9}$ during in the region $<50$ mol\% $\mathrm{Na}_{2} \mathrm{O}$. But at higher $\mathrm{Na}_{2} \mathrm{O}$ concentrations, $\mathrm{Na}_{2} \mathrm{Te}_{2} \mathrm{O}_{5}$ and $\mathrm{NaTeO}_{3}$ crystalline clustered phases in the nono size scale are the dominant types... In $\mathrm{Na}_{2} \mathrm{O}$-rich telluride network, Na coordination is the dominant process instead of breaking more tellurium-oxygen bonds.

\section{References}

[1] A Santic, A Mogus-Milankovi, K Furic, M Rajik-Linarik, Chandra S. Ray, and D E. Day, CROATICA CHEMICA ACTA, CCACAA 81 (4) 559-567 (2008)

[2] E R.Barney, A C.Hannon' D Holland' N Umesaki M Tatsumisago, Journal of Non-Crystalline Solids, Volume 414, 15 (2015) 33-41

[3][ A Kaur A Khanna' M Gonzále-Barriuso' F González', B Chen, Journal of Non-Crystalline Solids Volume 470, (2017)14-18

[4] G El-Damrawi, K Abdelnur and R M Ramadan, Silicon 2 (2018)1-6

[5] T. Sekiya, N. Mochida, A. Ohtsuka, and M. Tonokawa J. Non crystalline Solids 128 (1992).

[6] T Sekiya ,N Mochida, A Soejima, Journal of Non-Crystalline Solids Volume 191, 1-2, (1995) 115-123

[7] C. McLaughlin, S. L. Tag, and J. W. Zwanziger, Glasses J. Phys. Chem. B, 2001, 105 (1), pp 67-75

[8] M N. Garaga, U. Werner-Zwanziger, J. W. Zwanziger, A. De Ceanne, B. Hauke K. Bozer, and S. Feller, Journal of Physical Chemistry C 2017121 (50), 28117-28124

[9] G El-Damrawi, AK Hassan, S Ehmead, A El Shahawy, New Journal of Glass and Ceramics 7 (02), 22 
[10] T Uchino, T Yoko, Journal of Non-Crystalline Solids 204 (1996) 243-252

[11] S. L. Tagg, J. C. Huffman, and J.W. Zwanziger, Chem. Mater. 6 (1994) 1884-1889.

[12] S. L. Tagg, J. C. Huffman, and J.W. Zwanziger, Acta Chem. Scand. 51 (1997) 118-121.

[13] K.D. Dobbs and W.J. Hehre, J. Comput. Chem. 7 (1986) 359, and references therein.

[14] A karamanov and M Pelino, j.of European Ceramic Sociaty 19(1999) 649].

[15] M.J. Frisch, G.W. Trucks, M. Head-Gordon, P.M.W. Gill, M.W. Wong, J.B. Foresman, B.G. Johnson, H.B. Schlegel, M.A. Robb, E.S. Replogle, R. Gomperts, J.L Andres, K. Raghavachari, J.S. Binkley, C. Gonzalez, R.L. Martin, D.J. Fox, D.J. Defrees, J. Baker, J.J.P. Stewart and J.A. Pople, Gaussian 92, Revision C (Gaussian, Pittsburgh, PA, 1992). 